\title{
DETERMINAÇÃO ENZIMÁTICA DE DOPAMINA EM FORMULAÇÕES FARMACÊUTICAS UTILIZANDO SISTEMA DE ANÁLISE POR INJEÇÃO EM FLUXO COM EXTRATO BRUTO DE ABACATE (Persea americana)
}

Karina Omuro Lupetti, Luiz Antônio Ramos e Orlando Fatibello-Filho*

Departamento de Química, Universidade Federal de São Carlos, CP 676, 13565-905 São Carlos - SP

Recebido em 16/4/02; aceito em 4/9/02

\begin{abstract}
ENZIMATIC DETERMINATION OF DOPAMINE IN PHARMACEUTICAL FORMULATIONS USING A FLOW INJECTION ANALYSIS SYSTEM WITH AVOCADO (Persea americana) CRUDE EXTRACT. In this work, a spectrophotometric flow injection analysis system using a crude extract of avocado (Persea americana) as a source of polyphenol oxidase to dopamine determination was developed. The substrates and enzyme concentrations from $2.4 \times 10^{-7}$ to $5.3 \times 10^{-4} \mathrm{~mol} \mathrm{~L}^{-1}$ and 28 to 332 units $\mathrm{mL}^{-1}$ were evaluated, respectively. In addition, the FIA parameters such as sample loop (50 to $500 \mu \mathrm{L}$ ), flow rate (1.4 to $4.3 \mathrm{~mL} \mathrm{~min}^{-1}$ ) and reactor length $(100$ to $500 \mathrm{~cm})$ were also evaluated in a $0.1 \mathrm{~mol} \mathrm{~L}^{-1}$ phosphate buffer solution $(\mathrm{pH} 7.0)$. Dopamine solution concentrations were determined using 277 units $\mathrm{mL}^{-1}$ enzyme solution, $400 \mathrm{~mL}$ enzyme loop, $375 \mu \mathrm{L}$ sample loop, $2.2 \mathrm{~mL} \mathrm{~min}^{-1}$ flow rate and a reactor of $350 \mathrm{~cm}$. The analytical curve showed a linearity from $5.3 \times 10^{-5}$ to $5.3 \times 10^{-4} \mathrm{~mol} \mathrm{~L}^{-1}$ dopamine with a detection limit of $1.3 \times 10^{-5} \mathrm{~mol} \mathrm{~L}^{-1}$. The analytical frequency was $46 \mathrm{~h}^{-1}$ and the RSD lower than $0.5 \%$ for $5.3 \times 10^{-4} \mathrm{~mol} \mathrm{~L}^{-1}$ dopamine solution $(\mathrm{n}=10)$. A paired $\mathrm{t}$-test showed that all results obtained for dopamine in commercial formulations using the proposed flow injection procedure and a spectrophotometric procedure agree at the $95 \%$ confidence level.
\end{abstract}

Keywords: dopamine; flow injection analysis; crude extract.

\section{INTRODUÇÃO}

As enzimas são, em sua grande maioria, proteínas que catalisam com grande eficiência as reações metabólicas sob diversas condições de $\mathrm{pH}$, temperatura, meio iônico, entre outros ${ }^{1-5}$.

Toda enzima possui um centro ativo, local onde se processam as reações com determinado substrato. Este centro ativo é geralmente constituído de alguns resíduos de aminoácidos da cadeia protéica e de um grupo não-protéico, sendo responsável pela atividade biológica da enzima ${ }^{1-5}$

Algumas enzimas dependem somente de sua estrutura protéica para exercer sua atividade, enquanto outras necessitam também de um ou mais componentes não-protéicos chamados de cofatores, que podem ser íons metálicos ou moléculas orgânicas denominadas coenzimas. Algumas enzimas dependem de ambos. O complexo cataliticamente ativo enzima-cofator é denominado haloenzima ${ }^{1-5}$.

A enzima polifenol oxidase (PFO: E.C. 1.14.18.1) presente em grande quantidade em cogumelos, que na presença de oxigênio molecular causa oxidação de certos compostos, foi descoberta em 1895 por Bourquelot e Bertrand ${ }^{1}$. Ela é também chamada tirosinase, catecolase ou catecol oxidase e catalisa a oxidação tanto de monofenóis (e.g. tirosina, fenol, etc.) como difenóis (e.g. catecol, Ldopa, dopamina, adrenalina, etc.).

A PFO está presente em algumas bactérias e fungos, na maioria das plantas, em alguns artrópodes e mamíferos. Em todos estes casos, a enzima está associada com a pigmentação escura do organismo. Ela está presente, em concentrações altas, em cogumelo, batata, pêssego, maçã, banana, manga, abacate, folhas de chá e caféb.

A massa molar para as diferentes PFOs varia de 57 a $62 \mathrm{kDa}$, com exceção da PFO do cogumelo que apresenta $128 \mathrm{kDa}$, possuindo duas cadeias maiores com 43-45 kDa cada uma, onde estão os

*e-mail: bello@dq.ufscar.br sítios catalíticos, e duas menores com $13 \mathrm{kDa}$ cada uma ${ }^{6}$. A enzima apresenta-se como um complexo binuclear com dois átomos de $\mathrm{Cu}$ (II) no seu centro ativo, como apresentado no mecanismo proposto de oxidação de dopamina da Figura 1. A formação da dopaminaquinona depende tanto da concentração do oxigênio como da concentração da enzima ${ }^{7}$. Uma vez formada, a dopaminaquinona pode sofrer polimerização, levando à formação de melaninas.

A dopamina é um neurotransmissor central, precursor metabólico da noradrenalina e da adrenalina, que atua em receptores especí-

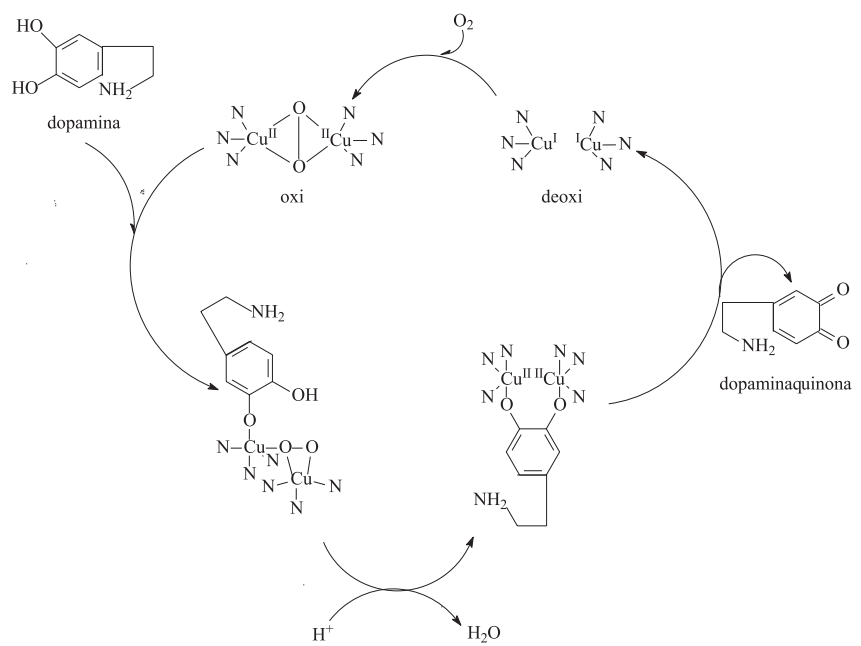

Figura 1. Mecanismo proposto de oxidação de dopamina pela enzima polifenol oxidase na presença de $\mathrm{O}_{2}$, adaptado da ref. 7. $\mathrm{O}$ sítio ativo da PFO apresenta $\mathrm{Cu}$ (I) na forma deoxi. Na presença de $\mathrm{O}_{2}$, ocorre a formação da espécie oxi, que catalisa a oxidação da dopamina, gerando a dopaminaquinona e regenerando a forma deoxi da PFO 
ficos, presentes no sistema nervoso central, nos vasos mesentéricos, renais e nas coronárias. É utilizada para o tratamento de diversos tipos de choque e da hipotensão grave após infarto agudo do miocárdio, dilatando os vasos sanguíneos renais e aumentando dessa forma o fluxo de sangue ${ }^{8}$. No Brasil, a dopamina é comercializada em forma de ampolas de $5 \mathrm{mg} \mathrm{mL}^{-1}$.

Diversas metodologias podem ser encontradas na literatura para determinação desse analito, dentre estas destacam-se os procedimentos em fluxo com detecção espectrofotométrica ${ }^{9-11}$, amperométrica ${ }^{12-17}$ e por quimiluminescência ${ }^{18-20}$. Ortega e Dominguez ${ }^{9}$ empregaram tirosinase imobilizada em reatores para determinação de dopamina por análise em fluxo com detecção espectrofotométrica e eletroquímica, apresentando limites de detecção de $3,5 \times 10^{-6} \mathrm{~mol} \mathrm{~L}^{-1}$ e $8,4 \times 10^{-6} \mathrm{~mol} \mathrm{~L}^{-1}$, respectivamente. Nevado e colaboradores ${ }^{10} \mathrm{em}-$ pregaram solução de metaperiodato em fluxo para detecção espectrofotométrica dessa catecolamina. O sistema apresentou um limite de detecção de $2,5 \times 10^{-6} \mathrm{~mol} \mathrm{~L}^{-1}$ e uma freqüência de amostragem de 130 determinações por hora. Uchiyama e Suzuki ${ }^{12}$ utilizaram extrato de folhas de espinafre como fonte de polifenol oxidase para a determinação amperométrica de dopamina. No entanto, 5 min de espera eram necessários para o retorno à linha base e início de nova injeção da solução de amostra. A linearidade do sistema em fluxo foi de $1,0 \times 10^{-4}$ a $6,0 \times 10^{-3} \mathrm{~mol} \mathrm{~L}^{-1}$. Montenegro e Sales ${ }^{15}$ empregaram um eletrodo seletivo $\mathrm{IO}_{4}^{-}$para a determinação potenciométrica de dopamina, obtendo-se uma linearidade no intervalo de concentração desse analito de $8,0 \times 10^{-3}$ a $2,7 \times 10^{-1} \mathrm{~g} \mathrm{~L}^{-1}\left(4,2 \times 10^{-5}\right.$ a $\left.1,4 \times 10^{-3} \mathrm{~mol} \mathrm{~L}^{-1}\right)$. Lima et al. ${ }^{16}$ desenvolveram eletrodos de carbono vítreo e pasta de carbono modificados com tecido vegetal de palmeira (Latania $s p$ ), como fonte enzimática para a determinação eletroquímica dessa catecolamina. $\mathrm{O}$ sistema em fluxo apresentou linearidade entre $5,0 \times 10^{-6}$ a $7,0 \times 10^{-5} \mathrm{~mol} \mathrm{~L}^{-1}$ de dopamina. Wang e Walcarius ${ }^{17}$ construíram eletrodos de pasta de carbono modificados com zeólitas para a determinação amperométrica desse fármaco. O sistema apresentou linearidade entre $2,0 \times 10^{-5}$ a $1,0 \times 10^{-3} \mathrm{~mol} \mathrm{~L}^{-1}$ com um tempo de residência de 45 s para pré-concentração em fluxo. Nozaki e colaboradores ${ }^{18}$ determinaram dopamina por meio da geração de peróxido de hidrogênio durante 30 min e detecção quimiluminescente do mesmo, na reação com peroxidase e luminol. O limite de detecção obtido foi de $1,0 \times 10^{-7} \mathrm{~mol} \mathrm{~L}^{-1}$, com um desvio padrão relativo de 4,7\% $(\mathrm{n}=5)$. Huang e colaboradores ${ }^{19}$ empregaram a inibição pela dopamina da propriedade quimiluminescente do sistema luminol-hipoclorito, obtendo um limite de detecção de $0,6 \mu \mathrm{g} \mathrm{L}^{-1}\left(3,2 \times 10^{-9} \mathrm{~mol} \mathrm{~L}^{-1}\right)$.

Desenvolveu-se nesse trabalho um sistema de análise por injeção em fluxo por zonas coalescentes para a determinação enzimática de dopamina em formulações farmacêuticas. Nesse procedimento, a enzima polifenol oxidase obtida do extrato bruto de abacate oxidou a dopamina à dopaminaquinona, que foi monitorada espectrofotometricamente em $466 \mathrm{~nm}$.

\section{PARTE EXPERIMENTAL}

\section{Equipamentos}

O abacate, fonte da enzima polifenol oxidase, foi homogeneizado em um liquidificador Walita, modelo Firenze RI6755. Usou-se na centrifugação desse material biológico, uma centrífuga Du Pont Instrumentos Sorvall, modelo RC-5B, provida de um rotor modelo SS-34 com diâmetro de $23 \mathrm{~cm}$.

As medidas espectrofotométricas foram feitas em um espectrofotômetro Femto, modelo $434 \mathrm{com}$ uma célula de fluxo de vidro (caminho óptico de $1,00 \mathrm{~cm}$ ) conectada a um registrador Cole Parmer (Niles, IL, USA), modelo 12020000 de dois canais. Para propulsão das soluções de referência, reagentes e amostras utilizou-se uma bomba peristáltica Ismatec (Zurich, Switzerland), modelo 7618-40 e tubos de extensão de Tygon de $0,8 \mathrm{~mm}$ de diâmetro interno. As amostras e soluções de referência foram introduzidas no sistema FIA, utilizando-se um injetor-comutador manual desenvolvido no CENAUSP, Piracicaba.

\section{Reagentes e soluções}

Para a determinação de dopamina em fluxo, preparou-se uma solução estoque de dopamina (Sigma) dissolvendo-se 0,0102 g desse reagente em um balão volumétrico de $10 \mathrm{~mL}$ com tampão fosfato $0,1 \mathrm{~mol} \mathrm{~L}^{-1}(\mathrm{pH} \mathrm{7,0)}$.

\section{Obtenção do extrato bruto de abacate}

Para obtenção do extrato bruto de abacate (Persea americana), fonte de polifenol oxidase, o seguinte procedimento foi adotado: uma massa de 25,0 g de polpa de abacate foi homogeneizada com $100 \mathrm{~mL}$ de tampão fosfato $0,1 \mathrm{~mol} \mathrm{~L}^{-1}(\mathrm{pH} 7,0)$ e $2,5 \mathrm{~g}$ de agente protetor Polyclar Super R, em um liquidificador, durante $3 \mathrm{~min}$. O homogenato foi filtrado em 4 camadas de gaze e centrifugado a $15000 \mathrm{rpm}$ durante $30 \mathrm{~min}$, a $4^{\circ} \mathrm{C}$. A solução sobrenadante foi dividida em diversas alíquotas, armazenadas em refrigerador a $4{ }^{\circ} \mathrm{C}$ e usadas como fonte enzimática ${ }^{20,21}$.

\section{Determinação de proteína total e atividade enzimática da PFO}

O teor de proteína total da solução sobrenadante foi determinado pelo método do biureto, empregando-se albumina de soro bovino como padrão ${ }^{22}$.

A atividade da polifenol oxidase foi determinada medindo-se a variação de absorbância $(\lambda=410 \mathrm{~nm})$ da quinona formada na reação enzimática. Nessa determinação foram usados $2,8 \mathrm{~mL}$ de solução de catecol 0,05 mol L-1 e 0,2 mL da solução sobrenadante (homogenato), a $25{ }^{\circ} \mathrm{C}$. Uma unidade de atividade (unidades $\mathrm{mL}^{-1}$ ) é definida como a quantidade de enzima que causa o aumento de 0,001 unidades de absorbância por minuto nas condições mencionadas.

Uma solução estoque de enzima PFO de 553 unidades $\mathrm{mL}^{-1}$ foi obtida a partir do extrato bruto enzimático concentrado de abacate.

\section{Métodos comparativos para determinação de dopamina}

Como métodos comparativos para a determinação de dopamina, foram utilizados o método proposto por Vieira e Fatibello ${ }^{20,21}$ e o método padrão da Farmacopéia Brasileira ${ }^{23}$. Dissolveu-se $5 \mathrm{~mL}$ da solução injetável Eurofarma em um balão volumétrico de $25 \mathrm{~mL}$ com solução tampão fosfato $0,1 \mathrm{~mol} \mathrm{~L}^{-1}(\mathrm{pH} 7,0)$. Construiu-se uma curva analítica a partir de uma solução padrão de dopamina $\left(5 \mathrm{mg} \mathrm{mL}^{-1}\right)$ variando-se a concentração das soluções de referência de 0,1 a $3,0 \mathrm{mg} \mathrm{mL}^{-1}$, adicionando-se as alíquotas da solução padrão diretamente na cubeta de quartzo com auxílio de uma micropipeta. Em seguida, completou-se o volume para $2,8 \mathrm{~mL}$ com solução tampão fosfato $0,1 \mathrm{~mol} \mathrm{~L}^{-1}(\mathrm{pH} 7,0)$ e por fim adicionaram-se $0,2 \mathrm{~mL}$ da solução de extrato bruto de batata doce (128 unidades $\mathrm{mL}^{-1}$ ) como fonte de polifenol oxidase. Foi cronometrado um tempo de 5 min e mediramse as absorbâncias do cromóforo (dopaminaquinona) formado em $470 \mathrm{~nm}$. O método da Farmacopéia consistiu em realizar as medidas de absorbância de dopamina diretamente em $280 \mathrm{~nm}$.

\section{Sistema de análise por injeção em fluxo}

O diagrama do sistema de análise por injeção em fluxo para determinação de dopamina é apresentado na Figura 2. 


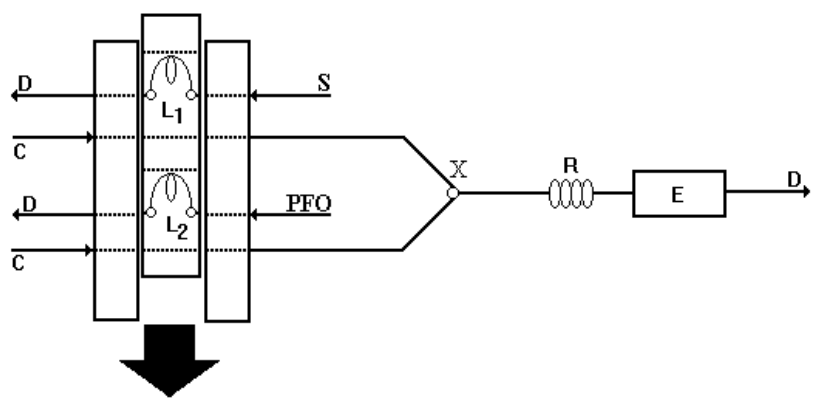

Figura 2. Diagrama de fluxos utilizado para a determinação espectrofotométrica de dopamina. $\boldsymbol{C}$, representa a solução transportadora (tampão

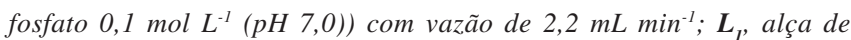
amostragem da solução de referência ou de amostra de $75 \mathrm{~cm}(375 \mu L) ; \boldsymbol{L}_{2}$, alça de amostragem da enzima de $80 \mathrm{~cm}(400 \mu \mathrm{L}) ; S$, soluções de referência ou de amostra; PFO, solução enzimática; $\boldsymbol{R}$, reator helicoidal de $350 \mathrm{~cm}$; $\boldsymbol{E}$, espectrofotômetro $(\lambda=466 \mathrm{~nm})$ e $\boldsymbol{D}$, descarte

Conforme pode ser observado no diagrama, as soluções de referência ou amostra, $\mathrm{S}$, contidas na alça de amostragem $\mathrm{L}_{1}$, de $75 \mathrm{~cm}$ $(375 \mu \mathrm{L})$ e a solução enzimática contida na alça $\mathrm{L}_{2}$, de $80 \mathrm{~cm}(400 \mu \mathrm{L})$ são inseridas no transportador, $\mathrm{C}$ (tampão fosfato, $\mathrm{pH} 7,0$ ) e após passarem pelo ponto de confluência $X$, dirigem-se ao reator $\mathrm{R}$, de $350 \mathrm{~cm}$ de comprimento. $\mathrm{O}$ produto formado (dopaminaquinona) na reação enzimática foi então monitorado espectrofotometricamente em $466 \mathrm{~nm}$.

Foram estudadas várias concentrações de substrato $\left(2,4 \times 10^{-7}\right.$ a $\left.5,3 \times 10^{-4} \mathrm{~mol} \mathrm{~L}^{-1}\right)$ e de enzima $(28 ; 42 ; 55 ; 83 ; 111 ; 138 ; 165 ; 208$; 221; 277 e 332 unidades $\mathrm{mL}^{-1}$ ), variando-se o comprimento das alças $\mathrm{L}_{1}$ e $\mathrm{L}_{2}(50,75,100,150,200,250,300,375,400$ e $500 \mu \mathrm{L})$. Estudou-se a vazão do carregador $(1,4 ; 1,8 ; 2,2 ; 2,7 ; 3,1 ; 3,5$ e 4,3 $\mathrm{mL} \mathrm{min}^{-1}$ ) variando-se a velocidade de propulsão da bomba peristáltica. E por fim, variou-se o comprimento do reator de $0,8 \mathrm{~mm}$ de d.i. $(100,200,250,300,350,400,450$ e $500 \mathrm{~cm})$. Construiu-se uma curva analítica para dopamina no intervalo de concentração de $5,3 \times 10^{-5}$ a $5,3 \times 10^{-4} \mathrm{~mol} \mathrm{~L}^{-1}$ e determinou-se então, a concentração de dopamina em ampolas Eurofarma ${ }^{\circledR}$, após diluição de 10 vezes em solução tampão fosfato $0,1 \mathrm{~mol} \mathrm{~L}^{-1}(\mathrm{pH} 7,0)$.

\section{RESULTADOS E DISCUSSÃO}

Para a determinação espectrofotométrica de dopamina usando a enzima PFO em fluxo com zonas coalescentes, foram otimizados alguns parâmetros do sistema em fluxo como concentração enzimática, comprimentos das alças de amostragem e da solução de PFO, vazão do sistema em fluxo e comprimento da bobina reacional.

\section{Efeito da concentração enzimática}

A atividade específica da PFO no abacate depende do grau de maturação dessa fruta, bem como da espécie estudada. Como estudado anteriormente por Lupetti ${ }^{24}$, a atividade específica aumenta com o grau de maturação até o estágio entre verde e maduro, diminuindo para os estágios avançados de maturação devido à degradação parcial da atividade dessa enzima.

A Figura 3 ilustra o efeito da concentração enzimática de PFO sobre o sinal analítico (absorbância) do sistema FIA. Estudou-se um intervalo de concentrações de 28 a 332 unidades $\mathrm{mL}^{-1}$, sendo então selecionado 277 unidades $\mathrm{mL}^{-1}$. Além da melhor resposta obtida nessa concentração enzimática, as medidas de absorbância apresentaram o menor desvio padrão relativo (RSD) e melhor relação sinal/ruído. Ademais, empregando-se esse extrato bruto, foi possível trabalharse durante um período de 6-7 h, sem perda da atividade enzimática.

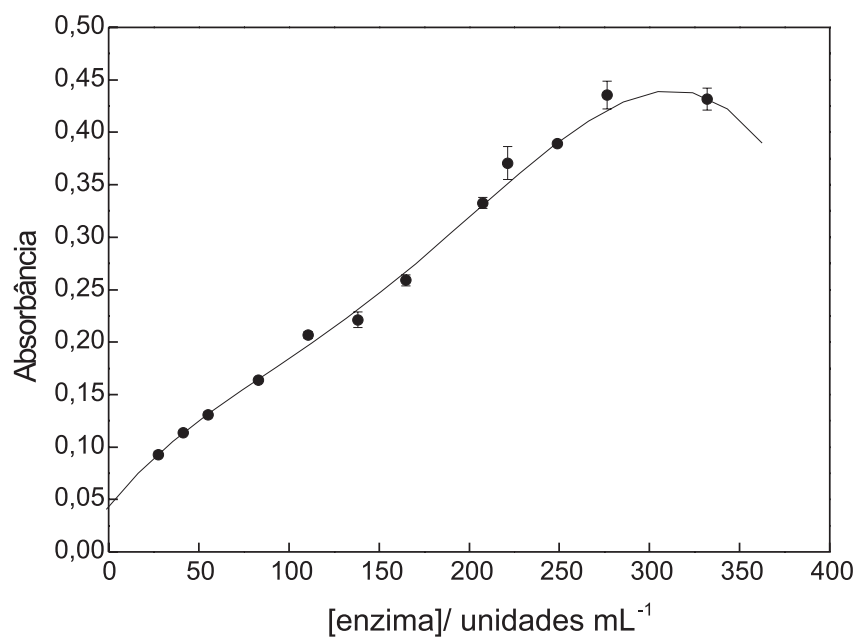

Figura 3. Efeito da concentração enzimática de 28 a 332 unidades $m L^{-1}$ sobre a resposta espectrofotométrica do sistema FIA, utilizando tampão fosfato pH 7,0 como transportador e dopamina $2,7 \times 10^{-4} \mathrm{~mol} \mathrm{~L}^{-1}(\lambda=466 \mathrm{~nm})$

\section{Efeito dos volumes das alças de amostragem e da solução de PFO}

O efeito dos volumes das alças de amostragem e da solução de PFO de 50 a $500 \mu \mathrm{L}$ sobre o sinal analítico foram investigados. O sinal analítico aumentou com o aumento do volume da alça de amostragem $\left(\mathrm{L}_{1}\right)$ até o volume de $375 \mu \mathrm{L}$, mantendo-se praticamente constante em volumes superiores. Sendo assim, trabalhou-se com esse volume de alça de amostragem, pois essa também proporcionou maior freqüência analítica, como previsto. $\mathrm{O}$ efeito do volume da alça da solução de PFO 277 unidades $\mathrm{mL}^{-1}$, no intervalo de 50 a 500 $\mu \mathrm{L}$ sobre o sinal analítico também foi investigado. A maior relação sinal/ruído foi obtida com $400 \mu \mathrm{L}$ de solução de PFO 277 unidades $\mathrm{mL}^{-1}$, para a alça de amostragem de $375 \mu \mathrm{L}$, mostrando ser esse volume suficiente para garantir maior eficiência da reação da enzima com o substrato. Sendo assim, selecionou-se esse volume de $\mathrm{L}_{2}$ para os estudos posteriores.

\section{Efeito da vazão do sistema FIA}

O efeito da vazão do carregador, variando de 1,4 a 4,3 $\mathrm{mL} \mathrm{min}^{-1}$, sobre o sinal analítico foi também estudado, sendo que este aumentou da vazão de 4,3 a 1,4 $\mathrm{mL} \mathrm{min}^{-1}$. Nesse trabalho foi selecionada a vazão de $2,2 \mathrm{~mL} \mathrm{~min}^{-1}$, uma vez que nessa vazão o sistema em fluxo apresentou maior repetibilidade e estabilidade da linha base.

\section{Estudo da bobina reacional}

Diferentes comprimentos de bobinas de reação variando de 100 a $500 \mathrm{~cm}$ foram também estudados. Como pode ser visto na Figura 4 , o reator de $350 \mathrm{~cm}$ possibilitou a obtenção de maior sinal analítico, sendo assim selecionado para estudos posteriores. Reatores de comprimentos inferiores a $350 \mathrm{~cm}$, provavelmente, não foram suficientes para o processamento da reação enzimática e os de comprimentos superiores devem ter causado maior dispersão da zona de amostra, diminuindo significativamente a magnitude do sinal analítico. No entanto, a queda acentuada do sinal analítico merece futuras investigações, pois o efeito da dispersão ao passar do reator (bobina 
reacional) de 350 para o de $400 \mathrm{~cm}$, não deveria levar a uma queda brusca de magnitude da absorbância.

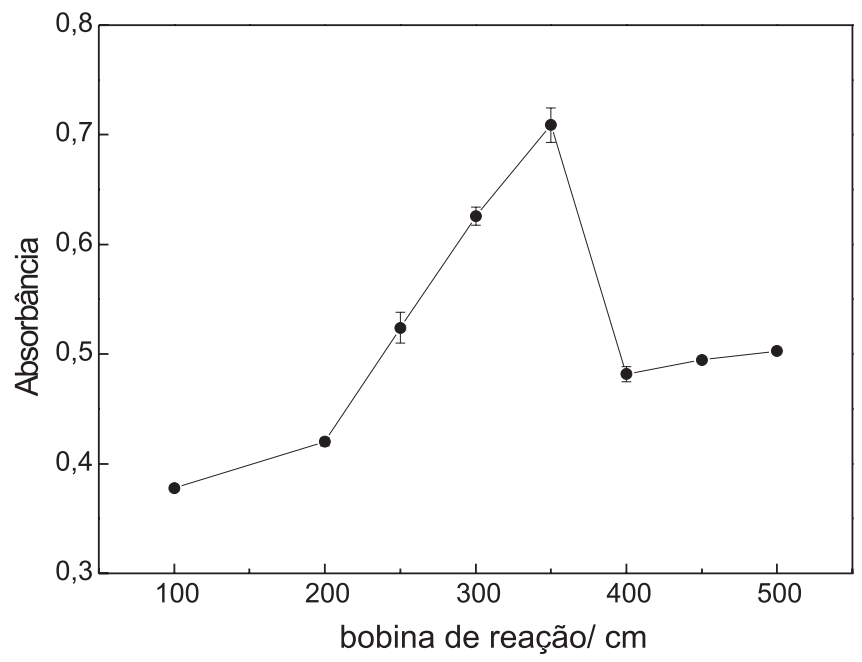

Figura 4. Estudo do comprimento da bobina de reação para determinação

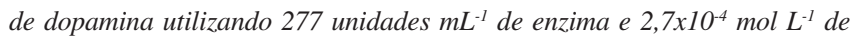
solução de referência

\section{Estudo da repetibilidade}

O sistema apresentou uma boa repetibilidade com RSD inferior a $0,5 \%$, após 10 injeções sucessivas de padrão de dopamina 5,3x $10^{-4} \mathrm{~mol} \mathrm{~L}^{-1}$.

\section{Determinação em fluxo de dopamina}

Empregando-se as melhores condições experimentais encontradas, i.e. bobina reacional de $350 \mathrm{~cm}$, concentração de PFO 277 unidades $\mathrm{mL}^{-1}$, alça de amostragem de $375 \mu \mathrm{L}$, alça da solução de PFO de $400 \mu \mathrm{L}$, vazão de $2,2 \mathrm{~mL} \mathrm{~min}^{-1}$, obteve-se a curva analítica para o procedimento FIA proposto. A Figura 5 apresenta os sinais transientes em triplicata para as soluções de referência de dopamina de $5,3 \times 10^{-5}$ a $5,3 \times 10^{-4} \mathrm{~mol} \mathrm{~L}^{-1}$, seguidos dos sinais transientes em triplicata das amostras A, B e C e, finalmente, sinais transientes das soluções de referência em concentrações decrescentes de $5,3 \times 10^{-4}$ a $5,3 \times 10^{-5} \mathrm{~mol} \mathrm{~L}^{-1}$.

A curva analítica apresentou uma linearidade de $5,3 \times 10^{-5}$ a $5,3 \times 10^{-4} \mathrm{~mol} \mathrm{~L}^{-1}$ de dopamina, com um limite de detecção de $1,3 \times 10^{-5} \mathrm{~mol} \mathrm{~L}^{-1}$ e pode ser descrita pela Equação 1:

$\mathbf{A}=0,06455+114,27 \mathbf{C}$

onde, A é a absorbância do composto formado, dopaminaquinona, C, a concentração de dopamina em $\mathrm{mol} \mathrm{L}^{-1}$ e $\mathrm{r}=0,9980$.

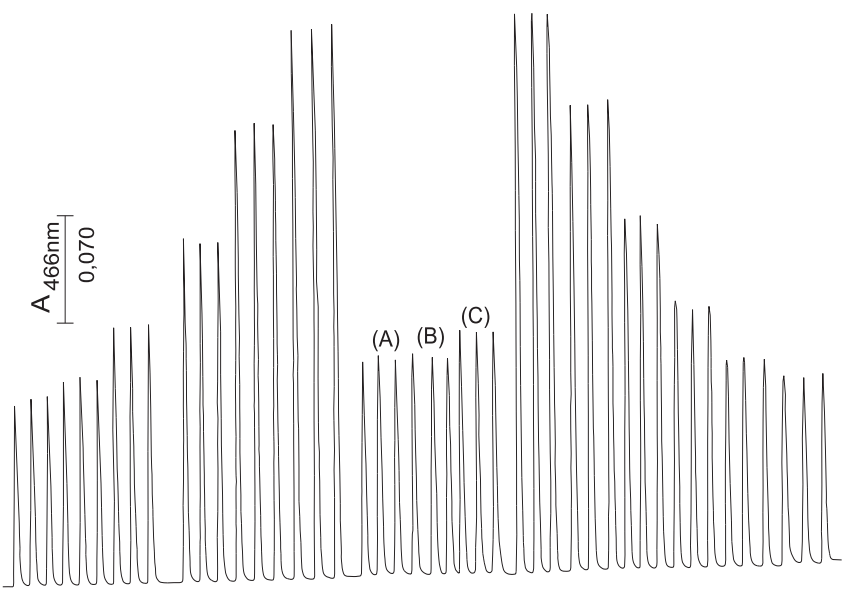

Tempo/ $\min$

Figura 5. Sinais transientes obtidos na determinação de dopamina, utilizando um sistema de zonas coalescentes com a enzima PFO. Da esquerda para direita, os sinais correspondem a triplicatas das soluções de referência

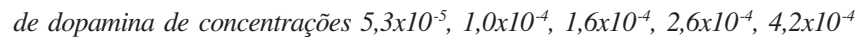

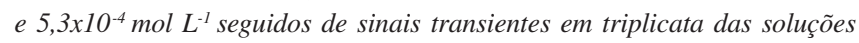
das amostras de dopamina Eurofarma ${ }^{\circledR}(A),(B)$ e $(C)$ e das soluções de referência novamente em concentrações decrescentes

A freqüência analítica foi de $46 \mathrm{~h}^{-1}$. A Tabela 1 apresenta os teores de dopamina em três produtos comerciais obtidos com um método enzimático em batelada ${ }^{21}$, o método padrão da Farmacopéia Brasilei$\mathrm{ra}^{23}$, com o procedimento FIA proposto e também os teores rotulados. Aplicando-se o teste t-pareado aos resultados obtidos empregando os métodos padrão e da literatura e o método proposto, verificou-se que esses resultados são concordantes a um nível de $95 \%$. Comparando-se os dados referentes a limite de detecção, linearidade e principalmente versatilidade, o método em fluxo proposto apresentou maior linearidade, menor LD e menor RSD que aquele trabalho anteriormente desenvolvido pelo grupo ${ }^{21}$ e maior freqüência analítica à metodologia padrão da Farmacopéia ${ }^{23}$, podendo ser utilizado na determinação de dopamina em formulações farmacêuticas.

\section{CONCLUSÕES}

Os estudos realizados neste trabalho evidenciaram a viabilidade do emprego do método espectrofotométrico enzimático em fluxo para a determinação de dopamina em amostras farmacêuticas. A freqüência analítica foi de $46 \mathrm{~h}^{-1}$, sendo utilizados apenas $400 \mu \mathrm{L}$ de solução enzimática 277 unidades de enzima $\mathrm{mL}^{-1}$ do extrato bruto de abacate e $375 \mu \mathrm{L}$ de amostra. Este procedimento apresentou boa repetibilidade $(\mathrm{RSD}<0,5 \%)$ para 10 injeções sucessivas de dopamina 5,3x $10^{-4} \mathrm{~mol} \mathrm{~L}^{-1}$, com um limite de detecção de $1,3 \times 10^{-5} \mathrm{~mol} \mathrm{~L}^{-1}$.

Tabela 1. Determinação de dopamina em ampolas farmacêuticas usando o método espectrofotométrico ${ }^{21}$, o método padrão ${ }^{23} \mathrm{e}$ o procedimento em fluxo proposto

\begin{tabular}{|c|c|c|c|c|c|c|c|}
\hline \multirow[b]{2}{*}{ Amostra } & \multicolumn{4}{|c|}{ Dopamina $\left(\mathrm{mg} \mathrm{mL}^{-1}\right)$} & \multicolumn{3}{|c|}{ Erros Relativos (\%) } \\
\hline & Rotulado & Espectr. & Padrão & Proposto & $\mathrm{E}_{1}$ & $\mathrm{E}_{2}$ & $\mathrm{E}_{3}$ \\
\hline $\mathrm{A}$ & 5,0 & $4,7 \pm 0,1$ & $4,8 \pm 0,1$ & $4,8 \pm 0,1$ & $-4,2$ & $+2,1$ & 0,0 \\
\hline $\mathrm{B}$ & 5,0 & $5,0 \pm 0,2$ & $5,0 \pm 0,1$ & $4,8 \pm 0,3$ & $-4,2$ & $-4,2$ & $-4,2$ \\
\hline $\mathrm{C}$ & 5,0 & $4,9 \pm 0,1$ & $5,0 \pm 0,1$ & $5,1 \pm 0,3$ & $+2,0$ & $+3,9$ & $+2,0$ \\
\hline
\end{tabular}

$\mathrm{n}=3$, nível de confiança $95 \% ; \mathrm{E}_{1}=$ proposto $v s$ rotulado; $\mathrm{E}_{2}=$ proposto $v s$ espectrofotométrico; $\mathrm{E}_{3}=$ proposto $v s$ padrão 


\section{AGRADECIMENTOS}

Os autores agradecem à FAPESP pelo auxílio financeiro e bolsa concedida à K. O. Lupetti (Proc. no 98/01252-1).

\section{REFERÊNCIAS}

1. Whitaker, J. R.; Principles of Enzymology for Food Sciences, Marcel Dekker: New York, 1972

2. Palmer, T.; Understanding Enzymes, John Wiley \& Sons: New York, 1985.

3. Voet, D.; Voet, J. G.; Biochemistry, $2^{\text {nd }}$ ed., John Wiley \& Sons: New York, 1995, p. 332

4. Stryer, L. W. H.; Biochemistry, $4^{\text {th }}$ ed., Freeman and Company: New York, 1995 , p. 181

5. Lehninger, A. L.; Princípios de Bioquímica, $2^{\text {nd }}$ ed., Savier: São Paulo, 1986, p. 154.

6. Araújo, M. A.; Química de Alimentos. Teoria e Prática, Imprensa Universitária da Universidade Federal de Viçosa: Viçosa, 1995, p. 247.

7. Ksower, E. M.; J. Am. Chem. Soc. 1985, 107, 4015.

8. Silva, P.; Farmacologia, $3^{a}$ ed., Guanabara: Rio de Janeiro, 1989, p. 241

9. Ortega, F.; Dominguez, E.; J. Pharm. Biomed. Anal. 1996, 14, 1157.
10. Nevado, J. J. B.; Gallego, J. M. L.; Laguna, P. B.; Fresenius' J. Anal. Chem. 1995, 353, 221.

11. Nevado, J. J. B.; Gallego, J. M. L.; Laguna, P. B.; J. Pharm. Biomed. Anal. 1996, 14,571

12. Uchiyama, S.; Suzuki, S.; Anal. Chim. Acta 1992, 261, 261.

13. Zimmerman, J. B.; Wightman, R. M.; Anal. Chem. 1991, 63, 24.

14. Hasebe, Y.; Takamori, K.; Uchiyama, S.; Anal. Chim. Acta 1993, 282, 363.

15. Montenegro, M. C. B. S. M.; Sales, M. G. F.; J. Pharm. Sci. 2000, 89, 876.

16. Lima, A. W. O.; Vidsiunas, E. K.; Nascimento, V. B.; Angnes, L.; Analyst 1998, 123, 2377

17. Wang, J.; Walcarius, A.; J. Electroanal. Chem. 1996, 407, 183.

18. Nozaki, O.; Kawamoto, H.; Moriyama, H.; Luminescence 1999, 14, 369.

19. Huang, J. C.; Zhang, C. X.; Zhang, Z. J.; Chin. Chem. Lett. 1998, 9, 843.

20. Vieira, I. C.; Tese de Doutorado, Universidade Federal de São Carlos, Brasil, 1997.

21. Vieira, I. C.; Fatibello-Filho, O.; Talanta 1998, 46, 559.

22. Gornall, A. G.; Bardawill, C. J.; David, M. M.; J. Biol. Chem. 1949, 177, 751.

23. Farmacopéia Brasileira, $3^{\mathrm{a}}$ ed., Organização Andrei Editora: São Paulo, 1977, p. 656-658.

24. Lupetti, K. O.; Dissertação de Mestrado, Universidade Federal de São Carlos, Brasil, 2000. 